\title{
ANALISIS EFISIENSI EKONOMI PENGGUNAAN FAKTOR-FAKTOR PRODUKSI PADA USAHATANI SEMANGKA MERAH DAN SEMANGKA KUNING DI GAPOKTAN NGUDI SANTOSO KABUPATEN PATI
}

\author{
Indri Aprilia, Edy Prasetyo dan Bambang Mulyatno S.
}

Program Studi S1 Agribisnis Fakultas Peternakan dan Pertanian Universitas Diponegoro, Semarang Email : indriaprilia961@gmail.com

\begin{abstract}
ABSTRAK
Tujuan penelitian ini untuk menganalisis pengaruh penggunaan faktor-faktor produksi lahan, benih, pupuk Phonska, pupuk Za, pestisida, dan tenaga kerja terhadap hasil produksi usahatani semangka merah dan semangka kuning, serta untuk menganalisis tingkat efisiensi ekonomi penggunaan faktorfaktor produksi usahatani semangka merah dan usahatani semangka kuning. Penelitian dilaksanakan pada bulan November 2017 di Gapoktan Ngudi Santoso Desa Bakalan Kecamatan Dukuhseti Kabupaten Pati. Metode penelitian yang digunakan adalah metode survei. Penentuan jumlah responden dilakukan dengan metode slovin, kemudian dari hasil tersebut ditetapkan sebagai kuota dengan metode quota sampling. Data yang digunakan adalah data primer dan data sekunder. Data primer diperoleh dari responden dengan wawancara menggunakan panduan kuesioner. Data sekunder diambil dari sumber atau instansi-instansi terkait serta dari pustaka lain yang berhubungan dengan penelitian ini. Analisis data menggunakan fungsi produksi model Cobb-Douglas, analisis regresi linier berganda dan independent sample t-test. Hasil dari penelitian yaitu penggunaan faktorfaktor produksi luas lahan, benih, pupuk Phonska, pupuk ZA, pestisida dan tenaga kerja secara serempak berpengaruh terhadap produksi semangka merah dan semangka kuning. Nilai signifikansi t-test efisiensi ekonomi lahan, benih, pupuk Phonska, pupuk ZA, pestisida, dan tenaga kerja usahatani semangka merah dan semangka kuning berturut-turut adalah 0,$001 ; 0,002 ; 0,000 ; 0,000$; 0,000 ; dan 0,000. Berdasarkan nilai tersebut menunjukkan bahwa terdapat perbedaan yang signifikan.
\end{abstract}

Kata Kunci: efisiensi ekonomi, faktor-faktor produksi, semangka merah, semangka kuning.

\begin{abstract}
The purpose of this study was to analyze the influence of the use of factors of land production, seeds, Phonska fertilizer, Za fertilizer, pesticides, and labor on the production of red watermelon and yellow watermelon farming, and to analyze the level of economic efficiency using the factors of red watermelon farming production. and yellow watermelon farming. The study was conducted in November 2017 at Ngudi Santoso Gapoktan Bakalan Village, Dukuhseti District, Pati Regency. The research method used is the survey method. Determination of the number of respondents is done by the Slovin method, then the results are determined as quota with the quota sampling method. The data used are primary data and secondary data. Primary data was obtained from respondents by interview using a questionnaire guide. Secondary data is taken from sources or related agencies as well as from other literature related to this research. Data analysis used the Cobb-Douglas model production function, multiple linear regression analysis and independent sample t-test. The results of the study, namely the use of factors of production of land area, seeds, Phonska fertilizer, ZA fertilizer, pesticides and labor simultaneously affect the production of red watermelon and yellow watermelon. The significance value of the t-test is the economic efficiency of land, seeds, Phonska fertilizer, ZA fertilizer, pesticides, and red watermelon and yellow watermelon farming labor. successively is 0.001; 0.002; 0,000; 0,000; 0,000; and 0,000. Based on these values indicate that there are significant differences.
\end{abstract}

Keywords: economic efficiency, production factors, red watermelon, yellow watermelon 


\section{PENDAHULUAN}

Salah satu subsektor pertanian yang terus digalakkan perkembangannya yaitu komoditi hortikultura. Tanaman hortikultura yang diusahakan para petani salah satunya adalah usahatani buah semangka.

Produktivitas usahatani semangka dapat mengalami peningkatan maupun penurunan. Hal tersebut salah satunya dipengaruhi oleh penggunaan faktor-faktor produksi yang kurang tepat dan kurang efisien (Mufrianti dan Anton, 2014). Pengalokasian penggunaan faktor-faktor produksi yang efektif dan efisien akan dapat menghasilkan produksi yang optimal, dengan produksi yang optimal maka pendapatan yang dihasilkan dari usahatani juga akan meningkat dan berkaitan erat dengan efisiensi dalam berusahatani (Efrizal et al., 2011).

Penelitian dilakukan di Gapoktan Ngudi Santoso Desa Bakalan Kecamatan Dukuhseti Kabupaten Pati. Pemilihan Desa Bakalan Kecamatan Dukuhseti sebagai lokasi penelitian karena merupakan wilayah yang lahannya digunakan sebagai sentra budidaya semangka dan Kecamatan Dukuhseti memiliki produksi semangka yang tinggi serta terdapat perbedaan produksi antara semangka merah dan semangka kuning di Kecamatan Dukuhseti. Produktivitas semangka di Gapoktan Ngudi Santoso Desa Bakalan tergolong masih rendah dan hasil produktivitasnya fluktuatif. Produktivitas semangka yang rendah dan fluktuatif salah satunya dipengaruhi oleh penggunaan faktorfaktor produksi yang kurang tepat dan kurang efisien. Faktor-faktor produksi yang dimiliki petani umumnya memiliki jumlah yang terbatas, tetapi disisi lain petani juga ingin meningkatkan produksi usahataninya. Hal tersebut menuntut petani untuk menggunakan faktor-faktor produksi yang dimiliki dalam pengelolaan usahatani secara efisien.

Peningkatan produksi dapat dilakukan melalui efisiensi produksi agar petani dapat menggunakan input produksi sesuai dengan ketentuan agar mendapatkan produksi yang optimal (Mufrianti dan Anton, 2014).

Tujuan dari penelitian ini adalah untuk menganalisis pengaruh jumlah penggunaan faktor-faktor produksi meliputi luas lahan, pupuk Phonska, pupuk ZA, benih, pestisida, dan tenaga kerja terhadap hasil produksi usahatani semangka merah dan semangka kuning, menganalisis tingkat efisiensi ekonomi dalam penggunaan faktor-faktor produksi usahatani semangka merah dan semangka kuning serta menganalisis perbandingan hasil efisiensi ekonomi semangka merah dan semangka kuning di Gapoktan Ngudi Santoso.

\section{METODE PENELITIAN}

Penelitian dilakukan pada bulan November 2017 sampai Desember 2017 pada usahatani semangka merah dan semangka kuning di Gapoktan Ngudi Santoso Desa Bakalan Kecamatan Dukuhseti Kabupaten Pati. Metode penelitian yang digunakan adalah metode survei yaitu penelitian yang mengambil sampel dari satu populasi dan menggunakan kuisioner. Penentuan jumlah sampel pada usahatani semangka merah dan semangka kuning ditentukan dengan metode slovin, kemudian dari hasil tersebut ditetapkan sebagai kuota dengan metode quota sampling. Metode quota sampling adalah teknik sampling yang menentukan jumlah sampel dari populasi yang memiliki ciri tertentu sampai jumlah kuota (jatah) yang diinginkan (Khairani, 2016). Sampel kuota yang telah diperoleh dipilih secara kebetulan dan sesuai karakteristik sampel dengan menggunakan metode accidental sampling. Metode accidental sampling adalah teknik penentuan sampel secara kebetulan atau siapa saja yang secara kebetulan bertemu dengan peneliti yang dianggap cocok dengan karakteristik sampel yang ditentukan akan dijadikan sampel (Sugiyono, 2015).

Rumus slovin yang digunakan adalah sebagai berikut: (Sukidin dan Mundir, 2005)

n = "N" /("1+N" "e" ^"2" )

Keterangan:

$\mathrm{n} \quad=$ ukuran sampel

$\mathrm{N} \quad=$ ukuran populasi

e $\quad=$ batas ketelitian yang diinginkan

(pada penelitian ini nilai e yang digunakan adalah sebesar 10\%)

Gapoktan Ngudi Santoso memiliki anggota sebanyak 186 orang yang terbagi dari 4 kelompok tani yaitu :

- Kelompok Tani Ngudi Santoso 1 yang beranggotakan 78 orang

- Kelompok Tani Ngudi Santoso 2 yang beranggotakan 30 orang

- Kelompok Tani Ngudi Santoso 3 yang beranggotakan 42 orang 
- Kelompok Tani Ngudi Santoso 4 yang beranggotakan 36 orang.

Berdasarkan perhitungan sampel menggunakan rumus slovin diperoleh 80 petani semangka sebagai responden. Jumlah 80 responden tersebut ditetapkan kuota setiap kelompok tani masing-masing diambil 20 responden, untuk mempermudah perhitungan, kemudian dibagi berdasarkan karakteristik masing-masing, sehingga diambil 10 petani semangka merah dan 10 petani semangka kuning dari masing-masing kelompok.

Analisis pengaruh faktor-faktor produksi dapat dianalisis menggunakan fungsi produksi model Cobb-Douglas yang digunakan untuk mengetahui pengaruh faktor produksi terhadap tingkat produksi semangka merah dan semangka kuning. Fungsi produksi model Cobb-Douglas yang digunakan sebagai berikut (Sumodiningrat, 2001) :

\section{$\mathrm{Y}=\mathrm{AX} 1 \mathrm{~b} 1 \mathrm{X} 2 \mathrm{~b} 2 \mathrm{X} 3 \mathrm{~b} 3 \mathrm{X} 4 \mathrm{~b} 4 \mathrm{X} 5 \mathrm{~b} 5$ X6b6 cu}

Analisis variabel diatas agar lebih mudah dalam perhitungan maka diubah menjadi logaritma natural (ln) sehingga variabel tersebut dapat di transformasikan kembali dengan menggunakan regresi berganda yang sebelumnya regresi di uji normalitasnya dengan uji asumsi klasik meliputi multikolinearitas, heteroskedastisitas, autokorelasi. Model regresi berganda yang digunakan menjadi sebagai berikut: $\mathrm{Y}=\mathrm{Ln} \mathrm{a}+\mathrm{b} 1 \operatorname{Ln} \mathrm{X} 1+\mathrm{b} 2 \operatorname{Ln} \mathrm{X} 2+\mathrm{b} 3 \operatorname{Ln} \mathrm{X} 3$ + b4 Ln X4 + b5 Ln X5 + b6 Ln X6 + u

Keterangan :

$\mathrm{Y}=$ produksi semangka $(\mathrm{kg} / \mathrm{MT})$

a $\quad=$ konstanta

$\mathrm{X} 1=$ luas lahan (ha)

X2 = benih $(\mathrm{kg} / \mathrm{MT})$

$\mathrm{X} 3=$ pupuk Phonska $(\mathrm{kg} / \mathrm{MT})$

X4 = pupuk ZA $(\mathrm{kg} / \mathrm{MT})$

X5 = pestisida (liter/MT)

X6 = tenaga kerja $(\mathrm{HOK} / \mathrm{MT})$

bi $=$ koefisien regresi

$\varepsilon \quad=$ bilangan natural $(2,718)$

$\mathrm{u} \quad=$ eror/kesalahan

Efisiensi ekonomi adalah besaran yang menunjukkan perbandingan antara keuntungan yang sebenarnya dengan keuntungan maksimum. Efisiensi ekonomi produksi terjadi pada saat nilai produk marjinal dari setiap unit tambahan masukan sama dengan harga dari setiap unit masukan tersebut (Soekartawi, 2003).

Efisiensi Ekonomi = "NPMxi" /"BKMxi" = ("Bxi.Y" /"Xi.Py" )/"Pxi" atau "MPP.Py" /"Pxi" = 1

Keterangan :

NPM = Nilai Produk Marjinal

Bxi = Koefisien regresi (b) masing-

masing variabel

$\mathrm{Xi} \quad=$ Faktor produksi

Py = Harga y atau harga produk

(produksi semangka)

BKMxi = Biaya Korbanan Marjinal faktor produksi

Pxi = Harga faktor produksi

Penggunaan faktor produksi tidak efisien jika Efisiensi Ekonomi < 1

Penggunaan faktor produksi sudah efisien jika Efisiensi Ekonomi = 1

Penggunaan faktor produksi belum efisien jika Efisiensi Ekonomi > 1

Analisis independent sample t-test merupakan salah satu bagian dari statistik inferensial parametrik (uji beda) yang digunakan untuk melakukan analisis terhadap data atau sampel yang tdiak saling berhubungan (Algifari, 2000).

Hipotesis varians uji beda yang diambil adalah sebagai berikut :

"H"_"0" : Tidak ada perbedaan yang signifikan antara efisiensi ekonomi usahatani semangka merah dan usahatani semangka kuning.

"H" _"1" : Terdapat perbedaan antara efisiensi ekonomi usahatani semangka merah dan usahatani semangka kuning.

Kriteria pengambilan keputusan varians uji beda yaitu :

"H" _"0" ditolak dan "H" _"1" diterima jika (signifikansi) $\leq 0,05$

"H" _"1" ditolak dan "H" _"0" diterima jika (signifikansi) $>0,05$

\section{HASIL DAN PEMBAHASAN \\ Semangka}

Semangka (Citrullus lanatus)

merupakan tanaman merambat yang berasal 
dari daerah Afrika. Tanaman ini masih sekerabat dengan labu-labuan (Cucurbitaceae). Tanaman semangka bersifat semusim, tergolong cepat berproduksi karena umurnya hanya enam bulan. Tanaman semangka tumbuh baik di dataran rendah hingga dataran tinggi 0 - 1000 meter diatas permukaan laut (Sunarjono, 2008). Saat ini di Indonesia telah banyak terdapat varietas semangka introduksi yang digolongkan menjadi semangka biasa, semangka hibrida dan semangka triploid (tidak berbiji). Semangka biasa merupakan hasil pembenihan masa suatu varietas secara alamiah contohnya seperti semangka merah dan semangka kuning. Tanaman ini cukup tahan akan kekeringan terutama apabila telah memasuki masa pembentukan buah (Kalie, 2008).

Gambaran Umum Daerah Penelitian

Desa Bakalan adalah sebuah desa pertanian yang termasuk salah satu desa penghasil semangka yang hasilnya dipasarkan ke daerah Pati, Kudus, Jepara dan daerah lain. Penduduk Desa Bakalan mata pencaharian utamanya adalah bertani padi tetapi saat musim kemarau mata pencaharian sampingan sebagai petani hortikultura. Luas wilayah Desa 308,818 ha, yang terbagi menjadi $3 \mathrm{Rw}$ dan 20 Rt. Total jumlah penduduk di Desa Bakalan 3.408 jiwa, dengan pembagian laki-laki sebesar 1.692 jiwa dan perempuan 1.716 jiwa. Gapoktan Ngudi Santoso merupakan sebuah gabungan kelompok tani yang berdiri resmi pada tanggal 1 Oktober 2005 di Desa Bakalan, Kecamatan Dukuhseti, Kabupaten Pati. Gapoktan Ngudi Santoso merupakan kelembagaan yang bergerak pada bidang pertanian padi dan hortikultura. Gapoktan Ngudi Santoso memiliki anggota sebanyak 186 orang yang terbagi dari 4 kelompok tani.

\section{Pengaruh Faktor-Faktor Produksi Terhadap Produksi Usahatani Semangka Merah}

Tabel 1. Hasil Uji Regresi Semangka Merah berdasarkan Koefisien Standarized

\begin{tabular}{llll}
\hline \hline Variabel & B & Sig. & VIF \\
\hline Konstanta & 3,657 & 0,052 & \\
& 0,272 & $0,014 *$ & 7,596 \\
Luas & & & \\
Lahan & & & \\
Benih & 0,227 & 0,107 & 6,168 \\
Pupuk & 0,211 & 0,232 & 8,211 \\
Phonska & & &
\end{tabular}

\begin{tabular}{llll} 
Pupuk ZA & 0,516 & $0,040 *$ & 8,331 \\
Pestisida & 0,224 & $0,005 *$ & 4,884 \\
Tenaga & 0,034 & 0,860 & 2,541 \\
Kerja & & & \\
\hline \multicolumn{2}{l}{$\mathrm{R}^{2}=0,905$} \\
\multicolumn{2}{l}{ Fhitung $=63,179$} \\
Sumber: Analisis Data Primer, 2018
\end{tabular}

Sumber: Analisis Data Primer, 2018

Keterangan : * Variabel berpengaruh nyata Sig $\leq 0,05$

Uji model regresi menggunakan uji koefisien determinasi, uji F, uji T dan uji asumsi klasik untuk mengetahui pengaruh faktor input terhadap produksi usahatani semangka merah. Uji asumsi klasik meliputi uji multikolinearitas, heterokedastisitas dan autokorelasi, sehingga memperoleh hasil uji regresi yang tertera pada Tabel 1 .

Berdasarkan data Tabel 1 dapat diketahui bahwa nilai signifikansi pada faktor produksi luas lahan, pupuk $\mathrm{Za}$, dan pestisida memiliki nilai lebih kecil dari $0,05(\alpha=5 \%)$ dengan demikian secara parsial luas lahan, pupuk Za, dan pestisida masing-masing berpengaruh nyata terhadap produksi semangka merah. Nilai signifikansi lahan (X1) sebesar 0,014, nilai signifikansi pupuk ZA (X4) sebesar 0,040, nilai signifikansi pestisida (X5) sebesar 0,005. Hal ini sesuai pendapat Sujarweni (2015) yang menyatakan bahwa nilai signifikansi $<0,05$ menunjukkan variabel independen secara parsial mempunyai pengaruh yang signifikan terhadap variabel dependen.

\section{Analisis Efisiensi Ekonomi Semangka Merah}

Tabel 2. Analisis Efisiensi Ekonomi Usahatani Semangka Merah

\begin{tabular}{|c|c|c|c|c|}
\hline $\begin{array}{l}\mathrm{N} \\
\mathrm{O}\end{array}$ & Variabel & NPM & $\mathrm{BKM}$ & $\begin{array}{l}\text { Efisiensi } \\
\text { Ekonomi }\end{array}$ \\
\hline & & ------Rp----- & -----Rp---- & \\
\hline 1 & Lahan & $14.457 .785,8$ & 5.000 .000 & 2,89 \\
\hline 2 & Benih & 8361625,39 & 900.000 & 9,29 \\
\hline 3 & $\begin{array}{l}\text { Pupuk } \\
\text { Phonska }\end{array}$ & 7084726,9 & 2.300 & 3080,32 \\
\hline 4 & $\begin{array}{l}\text { Pupuk } \\
\text { ZA }\end{array}$ & 12480652,7 & 1.800 & 6933,7 \\
\hline 5 & Pestisida & 13675171 & 400.000 & 34,19 \\
\hline 6 & $\begin{array}{l}\text { Tenaga } \\
\text { Kerja }\end{array}$ & 576663,8 & 75.000 & 7,69 \\
\hline
\end{tabular}

Sumber: Analisis Data Primer, 2018.

Berdasarkan Tabel 2 diketahui bahwa perbandingan nilai produk marjinal faktor produksi dengan harga faktor produksi berupa luas lahan sebesar 2,89; benih sebesar 9,29; 
untuk pupuk Phonska sebesar 3.080,32; pupuk ZA sebesar 6.933,7; untuk pestisida sebesar 34,19 dan untuk tenaga kerja sebesar 7,69, sehingga: NPM/BKM > 1, artinya penggunaan faktor-faktor produksi lahan, benih, pupuk Phonska, pupuk ZA, pestisida, dan tenaga kerja belum mencapai efisiensi ekonomi.

Nilai efisiensi ekonomi luas lahan, benih, pupuk Phonska, pupuk ZA, pestisida dan tenaga kerja memiliki nilai lebih dari 1 artinya kombinasi penggunaan faktor produksi yang berupa luas lahan, benih, pupuk Phonska, pupuk ZA, pestisida dan tenaga kerja pada usahatani semangka merah di Gapoktan Ngudi Santoso belum mencapai tingkat efisiensi ekonomi. Hal tersebut disebabkan oleh kurang maksimal dalam penggunaan faktor-faktor produksi pada usahatani semangka merah. Kurang maksimalnya penggunaan faktorfaktor produksi pada kenyataannya disebabkan oleh penggunaan input oleh petani yang tidak sesuai dengan dosis atau takaran yang dianjurkan untuk usahatani semangka merah. Hal ini sesuai dengan pendapat Soekartawi (2003) yang menyatakan bahwa apabila perbandingan nilai produk marginal faktor produksi dengan harga faktor produksi $>1$ maka artinya penggunaan faktor produksi $\mathrm{X}$ belum efisien dan perlu dilakukan penambahan faktor produksi X agar mencapai efisiensi ekonomi.

\section{Pengaruh Faktor-Faktor Produksi Terhadap Produksi Usahatani Semangka Kuning}

Tabel 3. Hasil Uji Regresi Semangka Kuning berdasarkan Koefisien Standarized

\begin{tabular}{|c|c|c|c|}
\hline Variabel & Koefisien & Sig. & VIF \\
\hline Konstanta & 8,707 & 0,000 & \\
\hline & 0,731 & $0,000^{*}$ & 4,677 \\
\hline $\begin{array}{l}\text { Luas Lahan } \\
\text { Benih }\end{array}$ & 0,387 & $0,023^{*}$ & 6,289 \\
\hline $\begin{array}{l}\text { Pupuk } \\
\text { Phonska }\end{array}$ & 0,110 & 0,605 & 8,480 \\
\hline Pupuk ZA & 0,156 & 0,434 & 6,524 \\
\hline Pestisida & 0,211 & 0,315 & 6,609 \\
\hline $\begin{array}{l}\text { Tenaga } \\
\text { Kerja }\end{array}$ & 0,281 & 0,089 & 2,784 \\
\hline \multicolumn{4}{|l|}{$\mathrm{R}^{2}=0,919$} \\
\hline
\end{tabular}

Sumber: Analisis Data Primer, 2018

Keterangan: * Variabel berpengaruh nyata Sig $\leq 0,05$

Berdasarkan data Tabel 3 dapat diketahui bahwa nilai signifikansi pada faktor produksi luas lahan dan benih memiliki nilai lebih kecil dari $0,05(\alpha=5 \%)$ dengan demikian secara parsial luas lahan dan benih masing-masing berpengaruh nyata terhadap produksi semangka kuning. Nilai signifikansi lahan (X1) sebesar 0,000 dan nilai signifikansi benih (X2) sebesar 0,023.

\section{Analisis Efisiensi Ekonomi Semangka Kuning}

Tabel 4. Analisis Efisiensi Ekonomi Usahatani Semangka Kuning

\begin{tabular}{|c|c|c|c|c|}
\hline No & Variabel & NPM & BKM & $\begin{array}{l}\text { Efisiensi } \\
\text { Ekonom }\end{array}$ \\
\hline & & ------Rp----- & -----Rp---- & \\
\hline 1 & Lahan & 17.350 .561 & 5.000 .000 & 3,47 \\
\hline 2 & Benih & $8.055 .617,45$ & 1.050 .000 & 7,67 \\
\hline 3 & $\begin{array}{l}\text { Pupuk } \\
\text { Phonska }\end{array}$ & 2.036 .035 & 2.300 & 885,23 \\
\hline 4 & $\begin{array}{l}\text { Pupuk } \\
\text { ZA }\end{array}$ & $2.714 .713,57$ & 1.800 & $1.508,17$ \\
\hline 5 & Pestisida & $-3.540 .930,7$ & 400.000 & $-8,85$ \\
\hline 6 & $\begin{array}{l}\text { Tenaga } \\
\text { Kerja }\end{array}$ & $3.954 .039,3$ & 75.000 & 52,72 \\
\hline
\end{tabular}

Sumber: Analisis Data Primer, 2018.

Berdasarkan Tabel 4 diketahui bahwa perbandingan nilai produk marjinal faktor produksi dengan harga faktor produksi berupa luas lahan sebesar 3,47, benih sebesar 7,67 untuk pupuk phonska sebesar 885,23 pupuk ZA sebesar 1.508,17 untuk pestisida sebesar 8,85 dan untuk tenaga kerja sebesar 52,72, sehingga: NPM/BKM > 1, artinya penggunaan faktor-faktor produksi $\mathrm{x}$ belum mencapai efisiensi ekonomi.

Nilai efisiensi ekonomi luas lahan, benih, pupuk phonska, pupuk ZA, dan tenaga kerja memiliki nilai lebih dari 1 artinya kombinasi penggunaan faktor produksi yang berupa luas lahan, benih, pupuk phonska, pupuk ZA, dan tenaga kerja pada usahatani semangka kuning di Gapoktan Ngudi Santoso belum mencapai tingkat efisiensi ekonomi. Nilai efisiensi ekonomi pestisida sebesar 8,85 artinya penggunaan faktor produksi variabel pestisida tidak efisien sehingga perlu dilakukan pengurangan pada faktor produksi pestisida. Hal ini sesuai dengan pendapat Soekartawi (2003) yang menyatakan bahwa apabila perbandingan nilai produk marginal faktor produksi dengan harga faktor produksi $<1$ maka artinya penggunaan faktor produksi $\mathrm{x}$ tidak efisien dan perlu dilakukan pengurangan faktor produksi $\mathrm{x}$ agar mencapai efisiensi ekonomi. 


\section{Uji Beda Efisiensi Ekonomi antara Usahatani Semangka Merah dan Semangka Kuning}

Tabel 5. Hasil dan Kesimpulan Uji Beda Efisiensi Ekonomi

\begin{tabular}{|c|c|c|c|c|}
\hline & \multicolumn{2}{|c|}{ "Efisiensi Ekonomi } & \multirow{2}{*}{$\begin{array}{l}\text { Hasil } \\
\text { Signifikansi } \\
\text { Uji Beda (t) }\end{array}$} & \multirow[b]{2}{*}{ Kesimpulan } \\
\hline & $\begin{array}{l}\text { Semangka } \\
\text { Merah }\end{array}$ & $\begin{array}{l}\text { Semangka } \\
\text { Kuning } \\
\end{array}$ & & \\
\hline $\begin{array}{l}\text { Lahan } \\
\text { (ha) }\end{array}$ & 2,89 & 3,47 & 0,001 & Signifikan \\
\hline $\begin{array}{l}\text { Benih } \\
\text { (kg/ha) }\end{array}$ & 9,29 & 7,67 & 0,002 & Signifikan \\
\hline $\begin{array}{l}\text { Pupuk } \\
\text { Phonska } \\
\text { (kg/ha) }\end{array}$ & 3080,23 & 885,23 & 0,000 & Signifikan \\
\hline $\begin{array}{l}\text { Pupuk } \\
\text { ZA } \\
\text { (kg/ha) }\end{array}$ & $6.933,7$ & $1.508,17$ & 0,000 & Signifikan \\
\hline $\begin{array}{l}\text { Pestisida } \\
\text { (liter/ha) }\end{array}$ & 34,19 & $-8,85$ & 0,000 & Signifikan \\
\hline $\begin{array}{l}\text { Tenaga } \\
\text { Kerja } \\
\text { (HOK) }\end{array}$ & 7,69 & 52,72 & 0,000 & Signifikan \\
\hline
\end{tabular}

Sumber: Analisis Data SPSS, 2018.

Berdasarkan Tabel 5 diperoleh hasil nilai signifikansi t-test efisiensi ekonomi lahan, benih, pupuk Phonska, pupuk ZA, pestisida, dan tenaga kerja usahatani semangka merah dan semangka kuning berturut-turut adalah 0,$001 ; 0,002 ; 0,000 ; 0,000 ; 0,000 ;$ dan 0,000 . Berdasarkan nilai tersebut menunjukkan bahwa terdapat perbedaan yang signifikan antara efisiensi ekonomi lahan, benih, pupuk Phonska, pupuk ZA, pestisida dan tenaga kerja pada usahatani semangka merah dan semangka kuning karena hasil signifikansi t-test kurang dari nilai 0,05 . Hal tersebut sesuai dengan pendapat Algifari (2000) yang menyatakan bahwa apabila nilai signifikansi t-test $\leq 0,05$ maka terdapat perbedaan antara data semangka merah dan data semangka kuning.

\section{SIMPULAN DAN SARAN}

Berdasarkan hasil penelitian pada usahatani semangka merah dan usahatani semangka kuning di Gapoktan Ngudi Santoso Desa Bakalan, Kecamatan Dukuhseti, Kabupaten Pati dapat ditarik kesimpulan bahwa penggunaan faktor-faktor produksi luas lahan, benih, pupuk phonska, pupuk ZA, pestisida dan tenaga kerja secara serempak berpengaruh terhadap produksi semangka merah dan semangka kuning. Secara parsial luas lahan, pupuk ZA, dan pestisida bepengaruh nyata terhadap produksi semangka merah. Penggunaan faktor produksi luas lahan, benih, pupuk phonska, pupuk ZA, pestisida dan tenaga kerja pada usahatani semangka merah belum mencapai efisiensi ekonomi. Secara parsial luas lahan dan benih bepengaruh nyata terhadap produksi semangka kuning. Penggunaan faktor produksi luas lahan, benih, pupuk phonska, pupuk ZA, dan tenaga kerja pada usahatani semangka kuning belum mencapai efisiensi ekonomi, sedangkan faktor produksi pestisida tidak efisien secara ekonomi. Nilai signifikansi t-test efisiensi ekonomi lahan, benih, pupuk Phonska, pupuk ZA, pestisida, dan tenaga kerja usahatani semangka merah dan semangka kuning berturut-turut adalah 0,$001 ; 0,002 ; 0,000$; 0,000; 0,000; dan 0,000. Berdasarkan nilai tersebut menunjukkan bahwa terdapat perbedaan yang signifikan antara efisiensi ekonomi lahan, benih, pupuk Phonska, pupuk ZA, pestisida dan tenaga kerja pada usahatani semangka merah dan semangka kuning karena hasil signifikansi t-test kurang dari nilai 0,05.

Beradasarkan hasil penelitian saran yang dapat diberikan adalah bahwa petani semangka merah di Gapoktan Ngudi Santoso masih dapat menambah penggunaan luas lahan, tenaga kerja, pestisida, benih, pupuk phonska dan pupuk za untuk meningkatkan produksi semangka merah. Sedangkan petani semangka kuning perlu melakukan pengurangan pada faktor produksi pestisida untuk meningkatkan produksi semangka kuning. Penambahan tenaga kerja agar tidak memperbesar biaya usahatani dapat dilakukan dengan meningkatkan kemampuan tenaga kerja secara kualitatif. Penggunaan luas lahan, benih, pestisida, pupuk phonska dan pupuk za yang digunakan dapat ditambahkan secara proporsional yang sesuai dengan kemampuan masing-masing petani dalam melaksanakan proses produksi, sehingga dapat meningkatkan nilai produksi usahatani semangka merah dan semangka kuning.

\section{DAFTAR PUSTAKA}

Algifari. 2000. Analisis Regresi, Teori, Kasus $\&$ Solusi. BPFE UGM, Yogyakarta.

Efrizal, Y., M. Nurung dan Gita M. 2011. Analisis pendapatan, efisiensi dan pemasaran semangka (Citrulus vulgaris) di Kampung Tempuran Kecamatan Trimurjo Kabupaten Lampung Tengah. J. Agrisep. 10 (2) : 273-286.

Kalie, M.B. 2008. Bertanam Semangka. Penebar Swadaya, Jakarta. 
Khairani. 2016. Penelitian Geografi Terapan. Kencana, Jakarta.

Mufrianti, F., dan Anton, F. 2014. Analisis faktor produksi dan efisiensi alokatif usahatani bayam (Amarathus Sp) di Kota Bengkulu. J. Agrisep 15 (1): 3137.

Soekartawi. 2003. Teori Ekonomi Produksi dengan Pokok Bahasan Analisis Fungsi Cobb Douglas. Raja Gravindo Persada, Jakarta.

Sugiyono. 2015. Metode Penelitian Kuantitatif, Kualitatif dan R\&D. Alfabeta, Bandung.
Sugiyono. 2016. Metode Penelitian Kuantitatif, Kualitatif dan R\&D. Alfabeta, Bandung.

Sujarweni, V.W. 2015. Metodologi Penelitian Bisnis dan Ekonomi. PT. Pustaka Baru, Yogyakarta

Sukidin dan Mundir. 2005. Metode Penelitian. Insan Cendikia, Surabaya.

Sumodiningrat, G. 2001. Metode Statistika. Pustaka Sinar Harapan, Jakarta.

Sunarjono, H. 2008. Berkebun 21 Jenis Tanaman Buah. Penebar Swadaya, Jakarta. 